\title{
An Exploration of the Potential Role of Digital Technologies for Promoting Learning in Foreign Language Classrooms: Lessons for a Pandemic
}

\author{
https://doi.org/10.3991/ijet.v15i14.13297 \\ Mary Masterson \\ University of Limerick, Limerick, Ireland \\ mary.masterson@ul. ie
}

\begin{abstract}
This study focuses on long-term digital technologies assisted cross-cultural communication as an instructional model. Secondary school foreign language learners of German and English collaborated online with the same age-cohort peers to acquire new cultural knowledge, as well as develop digital technologies skills. Findings revealed that digital technologies facilitated personalised student-led learning through an inquiry-based approach. Results further indicated that the learners had rich opportunities to share their stories and to think critically about themselves and others. Indeed, pupils enriched their understanding of their partner's culture as well as developing an enhanced understanding of the influence of culture on behaviour and thinking. The students learned to use digital technologies by creating digital profiles, posting their comments, asking questions, exchanging cultural information, and gaining linguistic and cultural experience of a native speaker in a virtual space. This paper shows that with the purposeful integration of digital technologies in foreign language classrooms opportunities for richer student learning experiences can be promoted. This is more relevant than ever before given the fallout and educational delivery challenges deriving from the current COVID-19 pandemic.
\end{abstract}

Keywords-Culture, digital technologies. online collaborative learning, COVID-19 pandemic.

\section{Introduction}

In a digital world there is a place for embedding technology into instruction [1].

Research demonstrates that technology can play a role in support of pedagogies focusing on learners in collaborative online learning environments [27]. [30] highlight the importance of digital technologies in education. [36] explains that students bereft of skills to navigate a complex digital landscape will be unable to participate fully in economic, social, and cultural life in the future. He further suggests that digital activities provide students with new ways to acquire digital technological skills and practice them. Adolescents spend considerable time using digital technologies outside the classroom [ 29]. As such, teachers have a captive audience for the implementation of technology into the classroom (13]. Utilising collaborative digital tools is an area that 
is becoming more popular in schools with the investment in technology in schools and teachers having access to programmes that facilitate online collaborative learning [12]. Digital technologies offer opportunities for online exchanges in schools and open up a space for intercultural learning [5].

Despite the movement internationally towards digital learning technologies, results from integration of technologies in European schools are not encouraging. Some schools still are unsure on how to embed digital technologies into instruction. As a [34] report states, many schools are inadequate in identifying methodologies that optimise the use of technology. Challenges such as overloaded curriculum, outdated technological equipment, and teacher inexperience of classroom digital technologies contribute to schools' failure to derive full benefit of new technologies $[36 ; 25]$.

A European Union initiative under the name eTwinning1 aims to promote new ways for digital use in European schools through encouraging online collaboration. Established in 2005 by the European Commission. Currently, 28 languages are incorporated, and 36 countries participate and there are 600,000 registered teachers in 2020 , with approximately 200,000 schools participating. Teachers can find ideas for projects or share their own ideas. Partners can be found, and a range of digital tools utilised for online project work. When a project is registered on the eTwinning digital platform, it gets a TwinSpace, which can only be accessed by project participants. In terms of safety and security, teachers act as moderators on the platform. Participants can only communicate in spaces that are controlled by teachers; this is useful for curtailing outside distractions from internet usage and ensuring online safety.

Specifically, in this study pupils aged 14-16 in upper secondary school in a foreign language classroom in Ireland and Germany, shared online their world views and had opportunities to probe their beliefs and values as they experienced their partners' perspective. There is merit in investigating technology use in the classroom, as learners increasingly employ technology to communicate with their peers and are comfortable with receiving content in that fashion [38]. How can foreign language educators, though, offer students opportunities to connect with native-speaking peers to learn together? Financially, having foreign language students connect and collaborate with native speakers in a virtual space from the comfort of their own classrooms makes eminent sense. The foregoing led to the following overall goal of the current study: enriching and internationalising foreign language curriculum for secondary school language students. Accordingly, the two main questions addressed in this paper are as follows: (1) Does the eTwinning school collaboration programme support language learners in developing new cultural knowledge? and (2) Did the digital capability of the participants improve?

New educational environments require different ways of designing learning experiences for students, as well as new approaches for teaching [32]. How can educators effectively engage their students in genuine knowledge creation and authentic inquiry [35]? Research suggests that inquiry-based approaches positively impact students' learning [16). Contemporary educational scholars promote myriad conceptual models

${ }^{1}$ eTwinning combines the prefix 'e-', which stands for electronic, and the word Twinning, which means "becoming friends". 
and alternatives subsumed under inquiry-based learning [20]. Although these approaches possess similarities, they rely on dissimilar definitions, of and pedagogical orientations to developing inquiry-based learning in practice.[14] encourages students to formulate problems related to their own experiences and augment their emerging understanding using personal knowledge. Inquiry-based learning for this study was conceptualised as an approach to learning that allows students' questions and curiosities to drive the learning [44]. Pupils' previous experience and knowledge were honored (4]. Previous research has shown that collaborative approaches to learning that are supported through digital technologies can positively impact students' learning $[15 ; 24 ; 46]$.

In the current investigation, learners were encouraged to question and make discoveries through interaction with their digital peers. They had a genuine audience in the target language community and met students of a similar age and learned from them; as such, they became aware of similarities and differences [49]. They shared knowledge and developed understanding through the virtual exchanges.

\section{Theoretical Framework}

The ABCs of Cultural Understanding and Communication [39] approach to intercultural learning was followed in the project [fig. 1]. First, each participant writes an autobiography describing key people, experiences, events, and memories from their life. Second, they interview a partner from a different culture to discover his/her life story and to write that person's biography where they give an account of their partners life as they understand it. They length of the biography is not defined, giving the individuals the space to explore another person's life as they perceive it. Third, learners compare this biography with their own autobiography to learn about cultural similarities and differences. Fourth, they construct a Venn diagram depicting these similarities and differences to facilitate an "in-depth self-analysis of cultural differences" [42, p. 5]. During this process, pupils reflect on any surprising, pleasant, or uncomfortable discoveries during the exchange with their partners. [41] indicates that the purpose of this step is to help participants begin to acquire insights about others and sense their own ethnocentrism (pp. 4-5). [40] explains that the ABC model focuses on "learning to view differences as special and as a means of celebrating the uniqueness of individuals" (p. 7).

The ABCs process was deemed to be the particularly suitable for this project, as at its core is the principle of inquiry-based learning. The learners co-operated in order to share their own personal stories and to learn from each other [31]. They had rich opportunities to reflect on themselves and others. This helped them to think about their own lives and to develop awareness of how previous experiences shape a person. The teacher supports the student by providing information, summarising responses and posing questions to encourage pupils to reflect [43]. 


\section{$3 \quad$ Methodology}

Capturing the complex nature of teachers' experiences of implementing a project requires a research approach that includes collection of rich, holistic data for in-depth analysis [11]. A qualitative and exploratory case study design was deemed apt for obtaining and interpreting data required to explore teachers' perceptions of how the project transformed pupils' cultural perceptions in tandem with the development of their digital technologies' skills [see 7]. In the context of this investigation, individuals were presumed to construct their own knowledge within the social-cultural context influenced by their prior knowledge and experiences. Language and digital media were vehicles for cultural learning. Students' autobiographies, emails, biographies, cross-cultural analysis materials, and post-project reflection were data sources as well as teachers' semi-structured interviews. These enabled cross-checking of observations with multiple data sources.

An online platform known as the TwinSpace was used to create a safe and secure e-learning environment in which the pupils worked together. A school in Ireland collaborated with a school in Germany, both having similar class sizes $(n=30)$. Sampling was purposive, and the interest group was a class of foreign language learners at upper secondary school level. Convenience strategies for sampling were used; selection of the student tandems was guided by considerations of availability [11]. Participants were from the same age group (14-16 years). Their proficiency levels were estimated, based on their performance on target language tests. On the Common European Framework of Reference for Languages [10], Irish students were at an A2, or an early level of proficiency; their German peers were at the higher BI level. Admittedly, there was a dissimilar level of language proficiency between the two groups. This phenomenon, however, was not germane, as the study focused on sharing and collaborating, where learners could individually increase their knowledge concurrently with improvement in language skills.

Participants followed the steps of the ABCs approach described in Appendix A. Exchanges comprised conversations via email, as well as joint completion of other written tasks (interviews of the partner, written biography of the partner, completion of cross-cultural analysis, and identification of similarities and differences between their life stories). The participants discussed topics of common interest, such as family, key life events, school, hobbies, etc. After the main tasks were completed, each learner wrote a reflection charting his/her cultural learning through exploring the connection between values, beliefs, practices and culture.

Communication took place in native speaker/non-native speaker tandems, although some pairs occasionally reverted to the mother tongue to maintain communication or to express themselves without being hampered by a perceived lack of foreign language proficiency. Students worked on the project in class, where teachers were available to provide linguistic support in the preparatory activities. Neither the teachers nor their students had to be proficient in digital technologies, as the National Support Service for the eTwinning programme was available to offer guidance in both countries. 
Students spent three 1.5-hour class periods per week over an eight-month period on the project. They employed asynchronous communication tools, such as email and discussion forums, to engage with their partners. The study was approved by the university ethics committee. Efforts to protect participants included obtaining parental and informed consent, asserting that participation was voluntary, ensuring anonymity of participants and schools, guaranteeing confidentiality and right to withdraw at any stage, and using private workspace offered by eTwinning (where only the partners, teachers, and researcher had access to the online exchanges).

The teacher's interview transcripts were analysed following [6] approach to thematic analysis [fig. 2]. Their perceptions provided insights illuminating aspects of learning that occurred during the study. Interrater reliability was enhanced by having three independent researchers code segments of the data. These researchers were experienced in coding qualitative data. Interrater agreement was $80 \%$. With the analytical process recorded in memos, the researcher could demonstrate the evolution of the themes or quickly retrieve data supporting a particular theme.

\section{$4 \quad$ Results}

In this study, the teachers' perceptions reveal how they view the digital technologies project as a way to create a greater appreciation for the diversity of experiences. Digital technologies provided the means to moving beyond classroom walls to inspire minds and to think about a country and a way of life in a new more differentiated and cross-cultural way.

\subsection{Personalised cultural learning}

A key finding noted by the teachers is that the use of digital technologies in the foreign language classrooms facilitated personalised cultural learning [48]. They found digital technologies encouraged their students to get to know a native speaker, recognising that for teenagers' friendships commonly start and are maintained digitally:

"We live in a digital age where teens use social media and mobile phones to meet and interact with their friends. If we want them to connect with other language learners, we should embrace technology in school and create opportunities for individual learners to progress at their own pace and according to their own interests. The leaners used their own voice in the project." T1

"Technology enabled personalised learning helped especially those pupils in class who are disengaged from school. Learning was improved for both classes as each learned from the others' personalised cultural experiences that are embedded in real life." T2

The students had the freedom to choose different paths to explore each other's life story. For example, one pair started this task by asking each other what a typical day was like for them, another pair explored each other's pastimes. Another pair started 
this task though enquiring about friendships they value and why. The personalised nature of the learning facilitated student engagement. Learning like this gave a boost to students as they followed in their conversations their own interests and did not have to stick to the suggestion of topics for discussion that the teacher had originally made available to them. There was room to go with a topic that was of interest to the group:

"The students have learning experiences that are personalised, applied and engaging. They enjoy typing up and exchanging messages on the iPads. I think this is a great way of including tech in the classroom." T1

"Students benefited from the personalised approach to learning, they engaged with their partner directly and received real-time feedback." T2

The freedom the pupils were given enabled insights to be shared in a manner that was relevant to the individuals in the specific partnership. Consequently, the pairs were able to bring in information that was personally of interest to them. The teachers felt students are more engaged when their learning related directly to the world, they live in and was student-led:

"The major advantage of the project is that students are very likely to get involved in activities they enjoy and find personally relevant to them." T1

"The learners themselves tailored the discussion threads to follow their own interests and goals. They communicated in a knowledge sharing virtual environment, which was student-led." T2

The students sometimes struggled with the language:

"They didn't always have sufficient vocabulary. So, I spent a lot of time developing their vocabulary and this coupled with support from their partners helped them learn a lot." T1

The teachers allowed the students to choose what language to use for interviewing their partner, most students choose to use the target language to complete this task. The students from Ireland used German and the students from Germany used English. One of the barriers with secondary school students collaborating with each other, is the issue of language and pupils being unable to express their opinions to one another, which can be frustrating and meant that some students were not always able to delve as deep in a topic as they might have needed to in order to keep the communication going. The pupils used translation apps (Google Translate) to help them express themselves which proved to be a useful tool and overcame the need for teachers to translate for their students.

"The students had control of which language for the exchanges with their partners. They used the target language most of the time ad their native speakers' partners helped. The google dictionary app supported them too." $T 1$

With the eTwinning programme linguistic and cultural experts who are native speakers engage in peer teaching. A teacher commented:

"Knowing people in the target language community is great - what a resource, it's a great way to tap into a different community. The class was willing to share their cultural expertise with the partner class. The information that they were exchanging was context-sensitive, so it was especially good to 
have the native speakers to give background information and to be able to answer questions." T1

However, tapping into another person's culture can led to misunderstandings.

"Misunderstandings can be reduced if the learners learn to ask questions that seek answers to cultural practices/attitudes that are different. Taking time to probe underlying reasons for these things will help to understand better cultural nuances." T1

"Going against the grain of unconscious conditioning is challenging. Challenging common stereotypes through questioning and discussion was a great cultural experience for the kids. " T2

Pupils need to be equipped with the tools and strategies to be able to appreciate the nuances of different cultures. Teachers have an active role to provide the learners with the necessary tools and strategies to develop an appreciation of the role of culture on shaping behaviour and attitudes:

"If we can learn to appreciate that other people's behaviour and attitudes stem from cultural differences, then common ground can be found. It's all about learning to respect difference." T1

"I think that for cultural learning to be effective it is critical to interrogate stereotypes, especially for this age group as adolescents are in the most formative years." $T 2$

\subsection{Embedding digital technologies in the classroom}

On-line tools would be quite new for some of the partners so there could be a need for more support from the National Support Service for the eTwinning programme to help the teachers familiarise themselves with the various digital technologies available to them through the programme. Different digital technology tools such as Kahoot for quizzes, Padlet, Infographics for poster design, Google Docs for working jointly on tasks, Google Sheets, or other collaborative tools are available so that the learners can work collaboratively with their partners. Communication tools such as email, forums, chat, video conference, blogs, wikis can be used for communication. The digital tools support communication in real time or through internal email or forums. Material can be uploaded onto the platform. Sharing the project products when it has been completed is also possible through blogs, school website, social media (Facebook, twitter).

The students' privacy was secured as only the members of the project had access to the TwinSpace. E-safety and the protection of participants was always a key consideration during the project. Personal details were not shared outside the TwinSpace and the public sharing of photos of participants was not permitted. Each school followed the e-safety guidelines for their individual school. Discussion about netiquette took place in each classroom prior to commencement of the project.

With eTwinning operates there is no issue with ensuring that pupils stay safe online as the TwinSpace is a closed group, access is only for the members and their teachers. The students can work at the same or different time as suited their own schedules. 
They reported on the success of the project in terms of creating a truly collaborative and authentic learning community:

"Pupils genuinely worked together online. They answered each other's questions and thought about what was the same and what was different, and could the reasons be for. They were thoughtful. It was not so much about the exchange of information, there was more of an interest in getting to know each other and comparing and analysing different cultural practices."

As [2] mentioned, co-operating with a peer possessing more cultural experience can be an effective means of supporting the process of co-constructing new cultural knowledge. This view is illustrated by a teacher's comment:

"Pupils were the experts and were teaching each other. They learned from each other, probably more than from relying on the textbook. It was interesting for them to learn first-hand about different cultural practices and norms." $\mathrm{T} 1$

In this way, the pupils developed their knowledge. Teachers commented that:

"Pupils enjoyed swapping their stories. They cared for the stories they exchanged. Seeing how their partners interpreted their stories was a valuable learning opportunity. Feeling appreciated helped keep the stories coming. New cultural knowledge was developed that helped them make sense of the foreign world." T2

Despite the positive dimension of experiencing another person's story, there needs to be review and reflection on the experience for learning [26]. Learning is a complex process that requires effective pedagogy [32]. One cannot simply assume that learning will occur.

One teacher observed that the learners developed competencies relevant for the future:

"We want our young people to know who they are, and what they value and why, to look beyond first impressions and to consider different perspectives. Doing a cultural exchange with a foreign partner is a good way to build-up skills and knowledge that will be useful in the future." T2

Pupils learned that unquestioning cultural stereotypes leads to misunderstandings and inaccurate assumptions being made. For the future to be able to questions takenfor-granted assumptions as a key skill for life in an increasingly diverse world.

The value of using a more immersive digital learning experience was acknowledged:

"It was a fun and rich learning experience. Meeting fellow students in the quest for knowledge. It inspired me too to use more often digital tools with my pupils." T1

One teacher explained that she got involved in the project as she saw it as something that gave her pupils opportunities to learn outside the classroom:

"Students learn to think twice, ask questions, and build selfunderstanding. They develop an appreciation of cultural differences and share perspectives with peers from a different culture." T2

The pupils learned how to navigate the digital learning platform and become more independent from the teacher: 
"Over time the pupils became very good at navigating the digital learning platform. Their digital skills developed as they became familiar with the various tools on the platform." T2

The teachers identified the value of using digital technologies to share learning and develop digital skills, although they did acknowledge that using digital technologies can be hard work and requires extra effort and commitment, especially in the early stages of a project [45]. It was an opportunity to gain knowledge through sharing and exploration of a different socio-cultural context. Digital technologies provided the tools for exploring stories and experiences from a cross-cultural perspective in order to promote understanding and develop an appreciation of different perspectives.

This investigation is subject to at least two limitations. Teachers and students might have benefited from training offered by the National Support Services for eTwinning. If it had been proffered, perhaps it could have led participants to use more tools offered by the platform. In addition, weaker students may have required more scaffolding from their teacher and/or from other learners to support them in the project [31].

\section{Discussion}

This research enhances knowledge in the field in several ways. First, our ability to thrive in an increasingly connected world depends on "helping the next generation to respect and embrace diversity rather than fear and reject differences" [17, pp. 488489]. Unfortunately, education systems tend to struggle with how best to prepare students for diversity [18]. Accordingly, there seemingly is a need to explore innovative inquiry-based pedagogical approaches to facilitate exploration of diversity. Doing so could aid learners to develop curiosity about cultures distinct from their own and thus gain appreciation for them. Teachers too can benefit as they collaborate with colleagues to plan and deliver online learning projects.

Many schools would like to embed digital technologies in to practice, however obstacles such as inadequate infrastructure, connectivity challenges and lack of technical support put barriers in the way of implementing digital technologies into teaching [12]. A first step though is to provide teachers with examples of actual projects they can easily incorporate into instruction and not to become disheartened with technological glitches occur. Most students have smart phones nowadays and they can be used to keep the project going until the technological issue is resolved. The current study provides teachers with an example of a project in action where pupils use digital technologies to learn in an active student-led manner.

Second, results of the current study highlight the potential offered by an inquirybased approach to educate through exposure to multiple perspectives in an online learning environment. The study demonstrated the significance of bringing the target language culture virtually into the foreign language classroom so that learners could get first-hand experiences of other cultures. This finding has implications for policy and practice where a strong case might be made for opening more foreign language classrooms to target language communities using digital technologies. Students interaction with age-cohort native speakers facilitated their motivation to learn each other's language in order to use it as a communication tool. 
Third, students took on the roles of cultural expert and novice in exchanges with partners. They scaffolded each other's learning by providing cultural meanings, thus guiding discovery and meaning making through co-construction processes [22]. The findings suggest that understanding and making connecting with others through online communication affords opportunities for students to become teachers, as they share cultural knowledge in a collaborative digital space. Accordingly, the foregoing thus begs the following questions: Should online collaboration with native-speaking peers be part of the foreign language classroom? How can policy makers promote such projects?

Although study findings cannot be generalized due to the small sample size and specific cultural contexts, they do show that there may well be merit in connecting learners through diverse digital tools and cultures. This investigation demonstrates that technologies afford benefits to adolescents by fostering active, social collaboration in digital learning spaces. This milieu seems fruitful for development of learners' intercultural, and digital skills in a student-centred inquiry-based approach to learning. [9] recommend that digital technologies projects be fully integrated with curriculum and instruction, and teacher professional development and coaching is essential for effective teaching and learning. The above becomes all the more pertinent in the wake of the current COVID-19 pandemic. In particular, as it impacts on requirements around social distancing, remote learning and the very continuity of educational programmes over the school year or semester. Could COVID-19 be the catalyst we need to fully embrace educational digitalisation?

\section{$6 \quad$ References}

[1] Alvermann, D. E., \& Sanders, R. K. (2019). Adolescent literacy in a digital world. The international encyclopedia of media literacy, New Jersey: Wiley-Blackwell, 1-6.

[2] Back, M. (2016). Epistemics and Expertise in Peer Tutoring Interactions: Co-Constructing Knowledge of Spanish. The Modern Language Journal, 100(2), 508-521. https://doi.org/ $10.1111 / \operatorname{modl} .12334$

[3] Bai, Y. (2018). On Modern Computer Assisted Language Learning Facilities and its Integrated Teaching. International Journal of Emerging Technologies in Learning (iJET), 13(11), 225-231. https://doi.org/10.3991/ijet.v13i11.8542

[4] Barron, B., \& Darling-Hammond, L. (2008). Teaching for meaningful learning: A review of research on inquiry-based and cooperative learning. Powerful learning: What we know about teaching for understanding (pp. 11-70). San Francisco, CA: Jossey-Bass.

[5] Bozdağ, Ç. (2018). Intercultural learning in schools through telecollaboration? A critical case study of eTwinning between Turkey and Germany. International Communication Gazette, 80(7), 677-694. https://doi.org/10.1177/1748048518802221

[6] Braun, V., \& Clarke, V. (2013). Successful qualitative research: A practical guide for beginners. London: Sage.

[7] Bryman, A. (2012). Social research methods. Oxford: Oxford University Press.

[8] Byram, M., \& Wagner, M. (2018). Making a difference: Language teaching for intercultural and international dialogue. Foreign Language Annals, 51(1), 140-151. https://doi.org/ 10.1111/flan.12319

[9] Chaia, A., Child, F., Dorn, E., Frank, M., Krawitz, M., \& Mourshed, M. (2017). Drivers of student performance: Latin America insights. CFC: Chile 
[10] Council of Europe (2001). Common European framework of reference for languages: Learning, teaching, assessment (CEFR). Retrieved from https://www.coe.int/en/web/por $\underline{\text { tal } / \text { home }}$

[11] Creswell, J. W. (2009). Research design: Qualitative, quantitative, and mixed methods approaches ( $3^{\text {rd }}$ ed.). London: Sage.

[12] Cosgrove, J., Moran, E., Feerick, E., \& Duggan. A. (2019). Digital Learning Framework (DLF) national evaluation - starting off: Baseline report. Dublin: Educational Research Centre.

[13] Department of Education and Skills (DES) (2019). Action plan for education 2019. Dublin: Author. Online at https://www.education.ie/en/the-department/action-plan-for-educati on-2016-2019/

[14] Dewey, J. (1938). Experience and education. New York, NY: Macmillan.

[15] Dooly, M. (2017). Telecollaboration. In Carol A. Chapelle \& Shannon Sauro (Eds.), The handbook of technology and second language teaching and learning (pp 169-183). Oxford,: Wiley Blackwell. https://doi.org/10.1002/9781118914069.ch12

[16] Edelson, D. C., Gordin, D. N., \& Pea, R. D. (1999). Addressing the challenges of inquirybased learning through technology and curriculum design. Journal of the Learning Sciences, 8(3-4), 391-450. https://doi.org/10.1207/s15327809j1s0803\&4_3

[17] Edwards, A. W. F. (2004). Cogwheels of the mind: The story of Venn diagrams. Baltimore, MD; London, UK: John Hopkins University Press.

[18] Faas, D., Sokolowska, B., \& Darmody, M. (2015). 'Everybody is available to them': Support measures for migrant students in Irish secondary schools. British Journal of Educational Studies, 63(4), 447-466. https://doi.org/10.1080/00071005.2015.1049974

[19] Finkbeiner, C., \& Lazar, A. M. (Eds.). (2015). Getting to know ourselves and others through the ABCs: A journey toward intercultural understanding. Charlotte, NC: Information Age Publishing. https://doi.org/10.1515/east-2016-0045

[20] Friesen, S., \& Scott, D. (2013). Inquiry-based learning: A review of the research literature. Edmonton, AB: Alberta Education, 1-32.

[21] Godwin-Jones, R. (2013). Integrating intercultural competence into language learning through technology. Language Learning \& Technology, 17(2), 1-11.

[22] Golonka, E. M., Tare, M., \& Bonilla, C. (2017). Peer interaction in text chat: Qualitative analysis of chat transcripts. Language Learning \& Technology, 21(2), 157-178.

[23] Gouseti A (2013) 'Old wine in even newer bottles': The uneasy relationship between Web 2.0 technologies and European school collaboration. European Journal of Education, 48(4), 570-585. https://doi.org/10.1111/ejed.12051

[24] Hauck, M., \& Satar, H. M. (2018). Learning and Teaching Languages in TechnologyMediated Contexts: The Relevance of Social Presence, Co-Presence, Participatory Literacy, and Multimodal Competence. In Screens and Scenes (pp. 133-157). Routledge. https:// doi.org/10.4324/9781315447124-7

[25] Kearney, C. (2016). Monitoring eTwinning Practice: A pilot activity guiding teachers' competence development. Brussels: Central Support Service of eTwinning - European Schoolnet.

[26] Kolb, D. A. (1984). Experiential learning: Experience as the source of learning and development (Vol. 1). Englewood Cliffs, NJ: Prentice-Hall.

[27] Kuhlthau, C. C., Maniotes, L. K., \& Caspari, A. K. (2015). Guided inquiry: Learning in the 21st century: Learning in the 21st century. Santa Barbara: ABC-CLIO.

[28] Kukulska-Hulme, A., \& Viberg, O. (2018). Mobile collaborative language learning: State of the art. British Journal of Educational Technology, 49(2), 207-218. https://doi.org/10.11 11/bjet.12580 
[29] Lenhart, A., Smith, A., Anderson, M., Duggan, M., \& Perrin, A. (2015). Teens, Technology and Friendships. Retrieved from https://www.pewresearch.org/internet/2015/08/06/tee ns-technology-and-friendships/

[30] Marcus-Quinn, A., Hourigan, T., and McCoy, S. (2019). The digital learning movement: How should schools respond? Economic and Social Review, 50 (4), 767-783.

[31] Masterson, M. (2017). Perception of the self and other and the role of language: An exploratory qualitative study. Frankfurt am Main: Peter Lang.

[32] Masterson, M. (2018). Self-Discovery Through the Experiential Co-Construction of Life Stories. Journal of Experiential Education., 41(4), https://doi.org/10.1177/1053825918785 $\underline{396}$

[33] Meyer, M.A, (1992). Negotiating of meaning: An intercultural and curricular problem. In D. Buttjes, W. Butzkamm \& F. Klippel (Eds.), Neue Brennpunkte des Englischunterrichts (pp 121 -129). Frankfurt: Peter Lang

[34] OECD (2015a). Students, Computers and Learning: Making the Connection, PISA, OECD.

[35] OECD (2015b). PISA 2015 Collaborative Problem-Solving Framework, PISA, OECD.

[36] Papadakis, S. (2016). Creativity and innovation in European education. Ten years eTwinning. Past, present and the future. International Journal of Technology Enhanced Learning, 8 (3-4), 279-296. https://doi.org/10.1504/ijtel.2016.082315

[37] Portera, A. (2014). Intercultural competence in education, counselling and psychotherapy. Intercultural Education, 25(2), 157-174. https://doi.org/10.1080/14675986.2014.894176

[38] Przybylski, A. K., \& Weinstein, N. (2017). A large-scale test of the goldilocks hypothesis: quantifying the relations between digital screen use and the mental well-being of adolescents. Psychological Science, 28(2), 204-215. https://doi.org/10.1177/0956797616678438

[39] Ruggiano Schmidt, P. (1998). The ABCs of cultural understanding and communication. Equity \& Excellence in Education, 31(20), 28-38.

[40] Ruggiano Schmidt, P. (1999). Focus on research: Know thyself and understand others. Language Arts, 76(4), 332-340.

[41] Ruggiano Schmidt, P. (2015). The origins of the ABCs: A crusade to develop compassionate educators. In C. Finkbeiner \& A. M. Lazar (Eds.), Getting to know ourselves and others through the ABCs: A journey toward intercultural understanding (pp. 1-10). Charlotte, NC: Information Age Publishing. https://doi.org/10.1515/east-2016-0045

[42] Ruggiano Schmidt, P., \& Finkbeiner, C. (Eds.). (2006). ABC's of cultural understanding and communication: National and international adaptations. Greenwich, CT: Information Age Publishing.

[43] Ruggiano Schmidt, P. R., Rodriguez, F., \& Sandroni, L. (2019). Encountering the ABCs and Meeting the Challenges. Practicing What We Teach: How Culturally Responsive Literacy Classrooms Make a Difference, 21.

[44] Rusche, S. N., \& Jason, K. (2011). 'You have to absorb yourself in it' Using inquiry and reflection to promote student learning and self-knowledge. Teaching Sociology, 39(4), 338-353. https://doi.org/10.1177/0092055x11418685

[45] Salim, K. R., Abdullah, M., Haron, H. N., Hussain, N. H., \& Ishak, R. (2019). A TeamTeaching Model in an Informal Cooperative Learning Classroom. International Journal of Emerging Technologies in Learning (iJET), 14(20), 44-57. https://doi.org/10.3991/ijet.v14 i20.11458

[46] Sauro, S., \& Chapelle, C. A. (2017). Toward langua-technocultural competence. The handbook of technology and second language teaching and learning, 459-472. https://doi. org/10.1002/9781118914069.ch30 
[47] Shrum, J. L., \& Glisan, E. W. (2015). Teacher's handbook, contextualized language instruction. Boston: Cengage Learning.

[48] Stickler, U. (2008). Chatting, chatten or chattare: Using a multilingual workspace for language and culture learning. International Journal of Emerging Technologies in Learning (iJET), 3(2008). https://doi.org/10.3991/ijet.v3i1.731

[49] Talalakina, E. (2010). Fostering Cross-Cultural Understanding Through E-Learning: Russian-American Forum Case-Study. International Journal of Emerging Technologies in Learning (iJET), 5(3), 42-46. https://doi.org/10.3991/ijet.v5i3.1290

[50] Woo, Y., \& Reeves, T. C. (2007). Meaningful interaction in web-based learning: A social constructivist interpretation. The Internet and Higher Education, 10(1), 15-25. https://doi. org/10.1016/j.iheduc.2006.10.005

\section{$7 \quad$ Author}

Mary Masterson is a lecturer and course director in the School of Education at the Faculty of Education and Health Sciences, University of Limerick, Limerick, V94 T9PX, Ireland. She is also a Leargás ambassador for the national eTwinning programme in Ireland, an initiative that fosters international school partnerships. Her research interests are digital technologies, diversity, and teacher well-being (e-mail: mary.masterson@ul.ie).

Article submitted 2020-01-21. Resubmitted 2020-02-22. Final acceptance 2020-02-22. Final version published as submitted by the author. 


\section{Appendix}

Table 1. The ABCs of Cultural Understanding and Communication Model Applied to the Current Study (Finkbeiner \& Lazar, 2015; Masterson, 2017; Ruggiano Schmidt, 1998, 1999; Ruggiano Schmidt \& Finkbeiner, 2006)

\begin{tabular}{|c|c|}
\hline Student Steps & $\begin{array}{c}\text { Part of the ABCs Model and Language Used to } \\
\text { Complete Task }\end{array}$ \\
\hline $\begin{array}{l}\text { Step 1: (A) Reflect on the self and write an } \\
\text { autobiography }\end{array}$ & Autobiography in the mother tongue of one's life story \\
\hline $\begin{array}{l}\text { Step 2: (B) Interview partner from other culture } \\
\text { with aim of writing partner's biography }\end{array}$ & $\begin{array}{l}\text { Biography in the foreign language based on an interview } \\
\text { of the partner }\end{array}$ \\
\hline Step 3: (C1) Conduct cross-cultural comparison & $\begin{array}{l}\text { Cross-cultural comparison in the foreign language } \\
\text { comparing similarities and differences depicted in Venn } \\
\text { diagram }\end{array}$ \\
\hline Step 4: (C2) Cultural self-analysis & $\begin{array}{l}\text { Cultural self-analysis of differences in the foreign lan- } \\
\text { guage }\end{array}$ \\
\hline
\end{tabular}

Table 2. Analytical Strategy for the Study

Phase 1: Open coding--broad participant-driven descriptive coding of the participants' autobiographies, emails, biographies, cross-cultural analysis material, and reflective essays into discrete codes

Phase 2: Selective coding--researcher-led coding of categories generated in Phase 1 into sub-catagorised coding

Phase 3: Consolidated coding--reorganizing, merging, renaming, and distilling categories from each of the sets of codes generated in phases $1 \& 2$ under the three major themes:

Codes that address extent to which participants reflected on themselves and their own culture

Codes that address extent to which participants reflected on their partner and his or her culture Codes that address extent to which participants enhanced digital skills

Phase 4: Written analytical memos (first draft of findings)

Phase 5: Validation of analytical memos (checking that findings accurately represent participants' voices)

Phase 6: Synthesis of analytical memos 